\title{
Serum amylase and lipase levels in healthy volunteers assessed by multiple commercial analyzers: Variability with established reference values
}

\author{
Vinod Kumar'; Mark A Gromski ${ }^{2 *}$; Chang-Il Kwon ; Michelle K Zimmerman ${ }^{4}$; Gail M McNulty ${ }^{2}$; Paul Korc ${ }^{5}$ Eun Kwang Choi ; \\ Jeffrey J Easler²; James Watkins²; Evan L Fogel'; Stuart Sherman²; Glen A Lehman² \\ ${ }^{1}$ Division of General Internal Medicine and Geriatrics, Indiana University School of Medicine, Indianapolis, IN, USA \\ ${ }^{2}$ Division of Gastroenterology and Hepatology, Indiana University School of Medicine, Indianapolis, IN, USA \\ ${ }^{3}$ Digestive Disease Center, CHA Bundang Medical Center, CHA University School of Medicine, South Korea. \\ ${ }^{4}$ Department of Pathology and Laboratory Medicine, Indiana University School of Medicine, Indianapolis, IN, USA \\ ${ }^{5}$ Hoag Hospital, Newport Beach, CA, USA \\ ${ }^{6}$ Department of Internal Medicine, Jeju National University College of Medicine, Jeju, South Korea.
}

\section{*Corresponding Author: Mark A Gromski}

Indiana University Hospital, 550 North University

Blvd., Suite 1634, Indianapolis, IN 46202-5149.

Tel: 1-317-944-0925, Fax: 1-317-948-0164;

Email: mgromski@iu.edu

Received: Jun 28, 2021

Accepted: Aug 12, 2021

Published: Aug 17, 2021

Archived: www.jjgastro.com

Copyright: (C) Gromski MA (2021).

Keywords: amylase; lipase; pancreatic enzymes; pancreatitis.

Abbreviations: RR: Reference Range; CLIA: Clinical Laboratory Improvements Amendments; FDA: Food And Drug Administration; CLSI: Clinical Laboratory And Standards Institute; IRB: Institutional Review Board.

\section{Abstract}

Background/Aims: Although serum pancreatic enzyme measurements for amylase and lipase are the most widely used biochemical tests for the diagnosis of pancreatitis, limitations for their interpretation of pancreatic disease do exist. An international reference method or an evidence-based cut-off value of serum pancreatic enzyme levels has not been established to facilitate standardization. Therefore, different analytic methods for serum pancreatic enzyme levels have verified their own Reference Ranges (RR) as normal values. The aim of this study is to evaluate the frequency of serum pancreatic enzyme values outside of the RR in healthy volunteers, using 5 different pancreatic enzyme analyzers to determine variability of values between analyzers.

Methods: Healthy volunteers were screened to exclude a history of pancreatic disease or pancreatic surgery, severe gastrointestinal disease, excess alcohol intake, tobacco use, amongst other conditions. Volunteers were prospectively enrolled and blood samples from a single draw were analyzed for serum pancreatic enzyme levels on five different automated chemistry analyzer platforms. Whether or not the results were within each analyzer's institutional RR was evaluated.

Results: Among screened healthy volunteers, 180 participants were enrolled who met the inclusion criteria. Serum amylase results were outside the RR in 8 (4.4\%), $11(7.2 \%), 19(10.5 \%), 6(3.3 \%)$ and $7(3.9 \%)$ subjects, respectively, based on the 5 separate analyzers. Serum lipase results were not within the RR in 3 (1.7\%), 20 (13.2\%), $13(7.2 \%), 1(0.6 \%)$ and $2(1.1 \%)$ subjects, respectively. Among all 22 $(12.2 \%)$ subjects that were outliers of the serum amylase level, 10 (5.6\%) of those subjects were outside of the RR for two or more analyzers. In contrast, among all $32(17.8 \%)$ subjects who were outliers 
Citation: Kumar V, Gromski MA, Kwon C, Zimmerman MK, McNulty GM, et al. Serum amylase and lipase levels in healthy volunteers assessed by multiple commercial analyzers: Variability with established reference values. Japanese J Gastroenterol Res. 2021; 1(3): 1011.

of serum lipase level, only four subjects (2.2\%) were outside of the RR for two or more analyzers.

Conclusion: Although there was slight variability in test results for serum amylase and lipase between different commonly available testing systems in healthy subjects, no values exceeded three times the upper limit of normal. There was a small group of healthy volunteers that fell outside of the reference range on two or more analyzers. If there is clinical ambiguity due to an abnormal serum pancreatic enzyme, further diagnostic testing can be pursued. Standardization amongst pancreas enzyme analyzers with a unified reference methodology and standard would be beneficial.

\section{Introduction}

The serum pancreatic enzyme measurements amylase and lipase are widely used in clinical practice and play an important role in the evaluation and diagnosis of pancreatitis [1,2]. Advantages of these enzyme measurements are technical simplicity, wide availability and low cost. However, using these enzymes as the "Gold Standard" method for the diagnosis or assessment of pancreatitis or pancreas disease has several limitations [3]. First, nonspecific elevation of serum pancreatic enzymes levels frequently occur in several non-pancreatic diseases and conditions [4]. Second, there are no internationally accepted enzyme activity measurement methodology or Reference Ranges (RRs). Therefore, there are multiple commercially available analytic methods and analyzers for serum pancreatic enzyme levels, which have their own different RRs as normal values.

Manufacturer's RRs are determined from a healthy population selected according to predefined criteria. However, since a manufacturer's reference population may not be comparable to an institution's population, the Clinical Laboratory Improvements Amendments (CLIA) of 1988 requires that, at a minimum, an institutional RR verification should be performed for unmodified US Food and Drug Administration (FDA) approved or cleared tests. An institutional RR establishment must be performed for modified FDA cleared or approved tests or lab developed tests. For RR verification, the Clinical Laboratory and Standards Institute (CLSI) guidelines recommend that institutions test 20 samples from members of their own healthy population. If two or fewer results fall outside of the manufacturer's claimed RR interval, then the RR is considered to be verified. For RR establishment, the CLSI guidelines recommend a minimum of 120 samples for each group or subgroup that requires characterization.

Despite significant literature on the utility of pancreatic enzymes in the diagnosis of acute pancreatitis, the head-to-head comparison of different available analytic techniques and analyzers has not been previously demonstrated. The aim of this study is to evaluate the frequency of values outside of the RR for pancreatic enzymes on 5 different chemistry analyzers using specimens from screened healthy volunteers, using the same specimen for each analyzer.

\section{Methods}

This study was approved by Indiana University Institutional Review Board (IU-IRB: 1310570729).

\section{Enrollment of healthy volunteers}

Healthy volunteers were screened and prospectively enrolled from September 1, 2013 to March 15, 2015. Informed consent was obtained from all healthy volunteers before enrollment. A general health/gastrointestinal health history survey was obtained from each prospective subject. Inclusion and exclusion criteria are listed in Table 1.

\section{Analysis of serum pancreatic enzymes}

Aliquots of blood samples from a single draw from each enrolled healthy volunteer were analyzed for serum pancreatic enzyme levels on five different automated chemistry analyzers (Table 2).

\section{Serum amylase analyzers}

\section{AU 5822 analyzer (Beckman Coulter, Inc., Brea, CA)}

This analyzer directly measures serum amylase activity by utilizing 2-chloro-4-nitrophenyl- $\alpha$-D-maltotrioside (CPNG3) as the substrate without the use of auxiliary enzymes [5-7]. The institution's reference range for amylase using this analyzer is $19 \mathrm{U} / \mathrm{L}-86 \mathrm{U} / \mathrm{L}$.

2. SYNCHRON ${ }^{\bullet}$ Systems UniCel ${ }^{\circledR}$ DxC 800 (Beckman Coulter, Inc. Brea, CA)

This analyzer measures serum amylase activity with an enzymatic rate method utilizing 4,6-ethylidene(G1)-4nitrophenyl(G7)- $\alpha$-(1 $\rightarrow 4)$-D-maltoheptaoside (ethylideneG7PNP) as the substrate [5]. The institution's reference range of this method is $36 \mathrm{U} / \mathrm{L}-128 \mathrm{U} / \mathrm{L}$.

3. Dimension Vista ${ }^{\circ}$ System (Siemens Healthcare Diagnostics, Inc., Tarrytown, NY)

This analyzer measures serum amylase activity using the previously described method where the CPNG3 is the substrate for amylase. The institution's reference range for this method is 28 $\mathrm{U} / \mathrm{L}-100 \mathrm{U} / \mathrm{L}$.

4. Roche/Hitachi cobas c systems (Roche Diagnostics, Indianapolis, IN)

This analyzer measures serum amylase activity with a similar enzymatic method as noted above, utilizing ethylidene-G7PNP as the substrate. The institution's reference range of this method is $25 \mathrm{U} / \mathrm{L}-115 \mathrm{U} / \mathrm{L}$.

5. Abbott Architect c16000 (Abbott Laboratories, Abbott Park, IL) 
This analyzer measures serum amylase activity with same method described above which uses CPNG3 as the substrate. The institution's reference range for this method is $25 \mathrm{U} / \mathrm{L}-125 \mathrm{U} / \mathrm{L}$.

\section{Serum lipase analyzers}

\section{5822 analyzer (Beckman Coulter, Inc., Brea, CA).}

This analyzer measures serum lipase level with the Imamura method where a di-glyceride substrate [11] is coupled to a series of enzymatic reactions with a resultant colorimetric measurement. The institution's reference range of this method is 7 U/L - $59 \mathrm{U} / \mathrm{L}$.

\section{SYNCHRON $^{\circledR}$ Systems UniCel ${ }^{\circledR}$ DxC 800 (Beckman Coulter,} Inc. Brea, CA)

This analyzer measures serum lipase level with the Panteghini methylresorufin analysis $[8,9]$. The institution's reference range of this method is $22 \mathrm{U} / \mathrm{L}-51 \mathrm{U} / \mathrm{L}$.

3. Dimension Vista ${ }^{\circledR}$ System (Siemens Healthcare Diagnostics, Inc., Tarrytown, NY)

This analyzer measures serum lipase with the Panteghini methylresorufin method. The institution's reference range of this method is $13 \mathrm{U} / \mathrm{L}-60 \mathrm{U} / \mathrm{L}$.

4. Roche/Hitachi cobas c systems (Roche Diagnostics, Indianapolis, IN)

This analyzer measures serum lipase with the Panteghini methylresorufin method. The institution's reference range of this method is $73 \mathrm{U} / \mathrm{L}-393 \mathrm{U} / \mathrm{L}$.

5. Abbott Architect c16000 (Abbott Laboratories, Abbott Park, IL)

This analyzer measures serum lipase level with the Imamura di-glyceride method. The institution's reference range is $8 \mathrm{U} / \mathrm{L}$ - $78 \mathrm{U} / \mathrm{L}$.

\section{Statistical analysis for subgroup comparison}

The one-way ANOVA test and student t-test were used to analyze the differences among the subgroups. Remaining variables were described as mean \pm Standard Deviation (S.D.). $\mathrm{P}<$ 0.05 was considered significant. Statistical analysis was performed with IBM ${ }^{\circledR}$ SPSS $^{\circledR}$ Statistics (Version 21.0.0; SPSS Inc., Chicago, IL, USA).

\section{Results}

A total of 186 healthy volunteers were enrolled. Six patients did not meet the inclusion/exclusion criteria after detailed review of their health history survey (after blood draw) and were excluded from final analysis. In total, 180 participants were included in final analysis. The 180 healthy volunteers consisted of 48 men $(26.7 \%)$ and 132 women (73.3\%), with a mean age of $48.3 \pm 15.7$ years (range, $20-78$ years). All 180 samples were successfully analyzed on five different analyzers, except for the second analyzer. The second analyzer was replaced during the enrollment period-152 total samples were analyzed on the second analyzer. The mean levels of serum amylase and lipase enzyme results for the five different analyzers are described in Table 3. Evaluation of age-related differences showed three of the five lipase analyzers having a significantly lower serum lipase in the young (18-39 yrs) age group when compared to the other two age groups (ages 40-59 and 60-79; $p$ values: <0.01-0.04), while all results of serum amylase levels related to age group were not significantly different. Evaluation of sex-related differences indicated two of the five lipase analyzers having significantly lower serum lipase result in females compared to males. The two lipase analyzers that had significant differences in regards to sex were different from the three lipase analyzers that showed significant differences in the age groups. All results of serum amylase levels were not significantly different between the sexes.

Table 4 describes the frequency of results outside of the RR on each analyzer. Individual serum amylase results were not within the institution's RR in the five different analyzers in $8(4.4 \%)$, 11 (7.2\% - this analyzer only had 152 subjects), 19 (10.5\%), 6 (3.3\%) and 7 (3.9\%) subjects, respectively. Serum lipase results were not within the RR in the five different analyzers in $3(1.7 \%)$, 20 (13.2\% - this analyzer was used in 152 subjects), 13 (7.2\%), $1(0.6 \%)$ and $2(1.1 \%)$ subjects, respectively (Table 4,5). Among the total $22(12.2 \%)$ patients that were outliers in the serum amylase RR level, 10 (5.6\%) of those subjects were outside of the RR for two or more analyzers. In contrast, among the total $32(17.8 \%)$ outliers of serum lipase level, only four subjects (2.2\%) were outside of the RR for two or more analyzers. Table 5 describes the specific values and the proportion above the reference range for each outlier. None of the values outside of the reference range reached three times the upper limit of normal.

\section{Discussion}

The interpretation of amylase and lipase can pose challenges. Values can be elevated in extra-pancreatic diseases [10]. Furthermore, interpretation of pancreatic enzymes becomes more difficult in the setting of chronic pancreatitis [11]. Complicating factors is that there is no accepted "Gold Standard" methodology for analyzing lipase and amylase levels. Depending on the methodology, the analyzer used and local population, reference ranges for the pancreatic enzymes amylase and lipase vary broadly [12]. This study was devised based on the anecdotal observation that a patient's pancreatic enzyme level can vary widely when coming from an outside referral hospital, when compared to the pancreatic enzyme levels drawn in our hospital. To further investigate this, we prospectively ran concurrent pancreatic enzyme tests on five different analyzers using healthy subjects, to determine what, if any, differences there may be between analyzers.

As can be seen in Table 1, we developed well-defined criteria with an attempt to exclude many factors previously known to affect serum amylase and lipase levels, and 180 healthy volunteers were enrolled prospectively to meet the CLSI guidelines ( $\geq 120$ subjects). One limitation of this study is that only $26.7 \%$ of the healthy volunteers were male, which is not uncommon in a study involving healthy volunteers. As presented in Table 3 , age and sex-related differences in pancreatic enzyme levels amongst healthy volunteers revealed that serum lipase levels were affected to some degree by the age and the sex of healthy volunteers, as reported previously [13]. Interestingly, the three analyzers that had significant differences in the age were different than the two that had significant differences in the sex.

Table 4 shows that for most analyzers using our cohort, there was less than $10 \%$ outside of the reference limit, conforming to the CLSI guidelines. Because reference intervals are typically based on a $95 \%$ central tendency, $5 \%$ of normals are expected to fall outside the reference limits, generally with $2.5 \%$ under the lower reference value and $2.5 \%$ above the upper reference value. However, single patient outliers for at least 2 test meth- 
ods were discovered in 10 (5.6\%) subjects for serum amylase and in 4 (2.2\%) subjects for serum lipase. Analyzer \#2 had 7.2\% and $13.2 \%$ of subjects outside of the reference range for amylase and lipase, respectively. Of the 31 total samples that were outside of the reference range for this analyzer between both amylase and lipase, 25 of those samples were lower than the reference range (the other 6 were higher than the reference range). Analyzer \#3 had $10.0 \%$ and $6.7 \%$ of subjects outside of the reference range for amylase and lipase, respectively. Of the 32 total samples that were outside of the reference range for this analyzer between both amylase and lipase, 28 of those samples were higher than the reference range (the other 4 were lower than the reference range). It appears that analyzers 2 and 3 have less than optimal institutional reference ranges with regards to normal subjects being outside of the reference range compared to the other 3 analyzers.

\section{Limitations}

This study has several limitations, including the fact that the healthy volunteers were not evenly distributed by sex. Racial, ethnic, geographical and environmental conditions, menstrual cycle, estrogen supplement, and allowable medication were not considered for the enrollment criteria of healthy volunteers. Furthermore, medications, alcohol and tobacco usage were all evaluated by self-report, which may be subjective. We did not perform any specific testing on outliers of amylase for macroamylasemia. Also, one of the five analyzers only had 152 of the total 180 subjects enrolled tested, due to its unavailability towards the end of the study period. Furthermore, this study did not examine the differences of values and testing characteristics of pancreatic enzyme analyzers in patients who had pancreatic disease, such as acute pancreatitis.

Table 1: Inclusion criteria and exclusion criteria for study enrollment.

\begin{tabular}{|c|c|}
\hline Inclusion criteria & $\begin{array}{l}\text { - } \quad \text { Age } 18 \text { through } 79 \text { years. } \\
\text { - } \quad \text { General good health determined by study physician. } \\
\text { - } \quad \text { Body weight } 110 \text { pounds }(50 \mathrm{~kg} \text { ) or greater. } \\
\text { - } \quad \text { Ablity to consent to study } \\
\text { - } \quad \text { Be willing to have bloodwork drawn. }\end{array}$ \\
\hline
\end{tabular}

Exclusion criteria

- History of gastrointestinal disorders: any pancreatic disorder, bowel obstruction or inflammatory bowel disease, peptic ulcer disease, gallstones or gastrointestinal tumors (any type).

- Acute or chronic kidney disease.

- History of ovarian tumors (any type).

- History of lung tumors (any type).

- Major health disorders: diabetes mellitus, liver disorders, rheumatoid arthritis (osteoarthritis acceptable), myocardial infarction, or chronic obstructive pulmonary disease (chronic bronchitis or emphysema).

- Family history of chronic pancreatitis or cystic fibrosis.

- Pain in the upper abdomen greater than 5 days per year.

- Alcohol intake greater than 2 standard drinks per day.

- History of alcohol use of 10 standard drinks per day for greater than 2 years.

- Does not wish to participate or does not wish to consent to having their blood utilized in future studies.

- Pregnancy.

- $\quad$ Tobacco use history of more than 1 pack per day for 5 years or more.

N.B. A standard alcohol drink is defined as $12 \mathrm{oz}$ of beer, $5 \mathrm{oz}$ of wine or $1.5 \mathrm{oz}$ distilled spirits.

Table 2: List of pancreas enzyme chemistry analyzers and methodologies.

\begin{tabular}{|c|c|c|c|}
\hline Analyzer Number & Chemistry analyzer & Amylase methodology & Lipase methodology \\
\hline 1 & AU 5822 analyzer (Beckman Coulter, Inc., Brea, CA) & CNPG3 enzymatic & Imamura di-glyceride \\
\hline 2 & $\begin{array}{l}\text { SYNCHRON DxC } 800 \text { analyzer (Beckman Coulter, Inc. } \\
\text { Brea, CA) }\end{array}$ & ethylidene-G7PNP enzymatic & Panteghini methylresorufin \\
\hline 3 & $\begin{array}{l}\text { Dimension Vista analyzer (Siemens Healthcare Diagnos- } \\
\text { tics, Inc. Tarrytown, NY) }\end{array}$ & CNPG3 enzymatic & Panteghini methylresorufin \\
\hline 4 & $\begin{array}{l}\text { Roche/Hitachi cobas c systems } \\
\text { (Roche Diagnostics, Indianapolis, IN) }\end{array}$ & ethylidene-G7PNP enzymatic & Panteghini methylresorufin \\
\hline 5 & $\begin{array}{l}\text { Abbott Architect c16000 analyzer (Abbott Laboratories, } \\
\text { Abbott Park, IL) }\end{array}$ & CNPG3 enzymatic & Imamura di-glyceride \\
\hline
\end{tabular}




\begin{tabular}{|c|c|c|c|c|c|c|c|c|c|}
\hline Enzyme & $\begin{array}{l}\text { Method Number } \\
\text { (Institutional RR) }\end{array}$ & $\begin{array}{c}\text { Total } \\
(\mathrm{n}=180)^{*}\end{array}$ & $\begin{array}{l}\text { Age 18-39 } \\
\qquad(n=60)\end{array}$ & $\begin{array}{l}\text { Age 40-59 } \\
\qquad(n=60)\end{array}$ & $\begin{array}{l}\text { Age } 60-79 \\
\qquad(n=60)\end{array}$ & $P$ value & $\begin{array}{l}\text { Male } \\
(n=48)\end{array}$ & $\begin{array}{l}\text { Female } \\
(n=132)\end{array}$ & $P$ value \\
\hline \multirow{5}{*}{ Serum Amylase } & $1(19-86, \mathrm{U} / \mathrm{L})$ & $50.7 \pm 17.8$ & $48.1 \pm 15.0$ & $50.6 \pm 16.7$ & $53.5 \pm 21.0$ & 0.25 & $51.3 \pm 22.9$ & $50.2 \pm 15.6$ & 0.82 \\
\hline & $2(36-128, U / L)$ & $72.4 \pm 25.2$ & $68.0 \pm 21.7$ & $72.3 \pm 24.9$ & $80.9 \pm 30.3$ & 0.07 & $72.6 \pm 28.9$ & $72.4 \pm 24.5$ & 0.96 \\
\hline & $3(28-100, \mathrm{U} / \mathrm{L})$ & $68.9 \pm 25.4$ & $64.7 \pm 20.6$ & $68.1 \pm 23.3$ & $73.8 \pm 30.6$ & 0.14 & $69.6 \pm 31.7$ & $68.6 \pm 22.7$ & 0.85 \\
\hline & $4(25-115, \mathrm{U} / \mathrm{L})$ & $62.3 \pm 21.5$ & $59.8 \pm 18.4$ & $62.1 \pm 20.4$ & $65.1 \pm 25.1$ & 0.41 & $62.8 \pm 27.5$ & $62.1 \pm 19.0$ & 0.89 \\
\hline & $5(25-125, \mathrm{U} / \mathrm{L})$ & $66.6 \pm 23.5$ & $64.2 \pm 20.7$ & $67.0 \pm 22.6$ & $68.6 \pm 27.0$ & 0.58 & $66.2 \pm 29.0$ & $66.7 \pm 21.3$ & 0.91 \\
\hline \multirow{5}{*}{ Serum Lipase } & $1(7-59, U / L)$ & $27.4 \pm 12.8$ & $24.2 \pm 10.7$ & $28.5 \pm 13.2$ & $29.5 \pm 14.0$ & 0.06 & $31.9 \pm 16.5$ & $25.8 \pm 10.8$ & 0.02 \\
\hline & $2(22-51, U / L)$ & $29.1 \pm 7.1$ & $27.3 \pm 6.0$ & $30.5 \pm 7.7$ & $29.9 \pm 7.2$ & 0.04 & $30.2 \pm 10.2$ & $28.8 \pm 6.1$ & 0.49 \\
\hline & $3(13-60, \mathrm{U} / \mathrm{L})$ & $37.0 \pm 12.9$ & $32.5 \pm 11.0$ & $39.5 \pm 13.0$ & $39.1 \pm 13.4$ & $<0.01$ & $39.9 \pm 17.5$ & $36.0 \pm 10.6$ & 0.15 \\
\hline & $4(73-393, \mathrm{U} / \mathrm{L})$ & $167.8 \pm 55.8$ & $150.1 \pm 51.6$ & $176.5 \pm 56.2$ & $176.9 \pm 56.3$ & 0.01 & $179.5 \pm 70.6$ & $163.6 \pm 49.0$ & 0.16 \\
\hline & $5(8-78, U / L)$ & $31.0 \pm 14.1$ & $28.0 \pm 12.0$ & $31.8 \pm 14.5$ & $33.3 \pm 15.2$ & 0.11 & $35.3 \pm 17.6$ & $29.5 \pm 12.3$ & 0.04 \\
\hline
\end{tabular}

Values are presented as mean values \pm S.D.

RR, Reference range; U/L, Units/Liter

Analyzer Key

1. AU 5822 analyzer

2. SYNCHRON ${ }^{\circledR}$ DXC 800 analyzer *Analyzer 2 had 152 samples examined

3. Dimension Vista ${ }^{\circledR}$ analyzer

4. Roche/Hitachi cobas c systems

5. Abbott Architect c16000 analyzer

Table 4: Frequency of individual amylase and lipase values below the lower reference limit or above the upper reference limit.

\begin{tabular}{|c|c|c|c|c|}
\hline \multirow{2}{*}{ Enzyme } & \multirow[t]{2}{*}{ Method number (Institutional RR) } & \multicolumn{3}{|c|}{ Number outside of the reference range (\%) $(n=180)^{*}$} \\
\hline & & Below LRL & Above URL & Total $p$ value \\
\hline \multirow{5}{*}{ Amylase } & $1(19-86, \mathrm{U} / \mathrm{L})$ & $0(0)$ & $8(4.4)$ & $8(4.4) \quad 1.00$ \\
\hline & $2(36-128, \mathrm{U} / \mathrm{L})$ & $6(3.9)$ & $5(3.3)$ & $11(7.2) 1.00$ \\
\hline & $3(28-100, U / L)$ & $2(1.1)$ & $17(9.4)$ & 19 (10.5) 0.0006 \\
\hline & $4(25-115, U / L)$ & $0(0)$ & $6(3.3)$ & $6(3.3) \quad 1.00$ \\
\hline & $5(25-125, U / L)$ & $1(0.6)$ & $6(3.3)$ & 7 (3.9) $\quad 0.12$ \\
\hline Total & & 9 & 42 & 0.00001 \\
\hline \multirow{5}{*}{ Lipase } & $1(7-59, U / L)$ & $0(0)$ & $3(1.7)$ & $3(1.7) \quad 1.00$ \\
\hline & $2(22-51, \mathrm{U} / \mathrm{L})$ & $19(12.5)$ & $1(0.7)$ & $20(13.2) 0.00$ \\
\hline & $3(13-60, \mathrm{U} / \mathrm{L})$ & $2(1.1)$ & $11(6.1)$ & $13(7.2) \quad 0.02$ \\
\hline & $4(73-393, U / L)$ & $1(0.6)$ & $0(0)$ & $1(0.6) \quad 1.00$ \\
\hline & $5(8-78, U / L)$ & $0(0)$ & $2(1.1)$ & $2(1.1) \quad 1.00$ \\
\hline Total & & 22 & 17 & 0.44 \\
\hline
\end{tabular}


Table 5: Amylase and lipase values below the lower reference limit (LRL) or above the upper reference limit (URL).

\begin{tabular}{|c|c|c|c|c|}
\hline & Below LRL & 1-2 times URL & 2-3times URL & >3times URL \\
\hline \multicolumn{5}{|l|}{ Amylase } \\
\hline 1. $(19-86, \mathrm{U} / \mathrm{L})$ & 0 & $8(87,90,92,93,101,107,121,143)$ & 0 & 0 \\
\hline 2. $(36-128, U / L)$ & $6(29,29,30,31,34,35)$ & $5(131,148,153,159,170)$ & 0 & 0 \\
\hline 3. $(28-100, U / L)$ & $2(23,27)$ & $\begin{array}{l}16(101,102,104,105,106,112,112,114, \\
121,121,123,126,138,143,156,159)\end{array}$ & $1(201)$ & 0 \\
\hline 4. $(25-115, \mathrm{U} / \mathrm{L})$ & 0 & $6(116,118,118,131,149,166)$ & 0 & 0 \\
\hline 5. $(25-125, \mathrm{U} / \mathrm{L})$ & $1(24)$ & $6(130,130,136,144,159,172)$ & 0 & 0 \\
\hline \multicolumn{5}{|l|}{ Lipase } \\
\hline 1. $(7-59, U / L)$ & 0 & $3(64,65,89)$ & 0 & 0 \\
\hline 2. $(22-51, \mathrm{U} / \mathrm{L})$ & $\begin{array}{c}19(15,17,17,18,18,20,20,20 \\
20,21,21,21,21,21,21,21,21,21 \\
21)\end{array}$ & $1(58)$ & $1(121)$ & 0 \\
\hline 3. $(13-60, \mathrm{U} / \mathrm{L}$ & $2(12,12)$ & $11(61,61,61,62,64,65,67,67,76,76,95)$ & 0 & 0 \\
\hline 4. $(73-393, U / L)$ & $1(67)$ & 0 & 0 & 0 \\
\hline 5. $(8-78, \mathrm{U} / \mathrm{L})$ & 0 & $2(79,93)$ & 0 & 0 \\
\hline
\end{tabular}

\section{Conclusion}

In conclusion, there is some variability in test results between different commonly available testing platforms. There was a small group of healthy volunteers that fell outside of the reference range on two or more analyzers. Two of the five analyzers have less than optimal institution's reference ranges with regard to frequency of outlier samples compared to the others. Nevertheless, none of the healthy subjects had a value that was three times the upper limit of the reference range. Thus, given the variability of testing for amylase and lipase, if a patient without symptoms of pancreas or extra-pancreatic disease has an abnormal serum pancreas enzyme test that creates diagnostic uncertainty, the clinician could discuss the patient's lab results with the institutional pathologist or clinical chemist. Further diagnostic testing may be indicated. Furthermore, there would be benefit for harmonization or standardization between manufacturers of pancreatic enzyme analyzers, with a unified reference methodology and reference standard.

Conflict of interest: None of the authors have declared any competing interests related to this manuscript. None of the authors have financial involvement.

Author contributions: *Vinod Kumar and Mark Gromski contributed equally to the article in study design, data collection, data analysis and manuscript writing.

\section{References}

1. Frossard JL, Steer ML, Pastor CM. Acute pancreatitis. Lancet. 2008; 371: 143-152.

2. Matull WR, Pereira SP, O'Donohue JW. Biochemical markers of acute pancreatitis. J Clin Pathol. 2006; 59: 340-344.

3. Yadav D, Agarwal N, Pitchumoni CS. A critical evaluation of laboratory tests in acute pancreatitis. Am J Gastroenterol. 2002; 97: 1309-18.
4. Vissers RJ, Abu-Laban RB, McHugh DF. Amylase and lipase in the emergency department evaluation of acute pancreatitis. J Emerg Med. 1999; 17: 1027-37.

5. Foo AY, Bais R. Amylase measurement with 2-chloro-4-nitrophenyl maltotrioside as substrate. Clin Chim Acta. 1998; 272: 137-47.

6. Lorentz K, Gütschow B, Renner F. Evaluation of a direct alphaamylase assay using 2-chloro-4-nitrophenyl-alpha-D-maltotrioside. Clin Chem Lab Med. 1999; 37: 1053-62.

7. Lorentz K. Approved recommendation on IFCC methods for the measurement of catalytic concentration of enzymes. Part 9. IFCC method for alpha-amylase (1,4-alpha-D-glucan 4-glucanohydrolase, EC 3.2.1.1). International Federation of Clinical Chemistry and Laboratory Medicine (IFCC). Committee on Enzymes. Clin Chem Lab Med. 1998; 36: 185-203.

8. Panteghini M, Bonora R, Pagani F. Measurement of pancreatic lipase activity in serum by a kinetic colorimetric assay using a new chromogenic substrate. Ann Clin Biochem. 2001; 38: 365-70.

9. Panteghini M. Pagani F, Bonora R. Clinical and analytical evaluation of a continuous enzymatic method for measuring pancreatic lipase activity. Clin Chem. 1993; 39: 304-8.

10. Hiatt JR, et al. The amylase profile: A discriminant in biliary and pancreatic disease. Am J Surg. 1987; 154: 490-2.

11. Tietz NW. Support of the diagnosis of pancreatitis by enzyme tests-old problems, new techniques. Clin Chim Acta. 1997; 257: 85-98.

12. Hein J, et al. Reference ranges for laboratory parameters in ferrets. Vet Rec. 2012; 171: 218.

13. Völzke H. et al. Prevalence and determinants of increased serum lipase levels in a general population. Pancreas. 2008; 37: 411-7. 